\title{
The effect of aging on verbal fluency in South Indians.
}

\author{
Suzanne Maria D'cruz ${ }^{1}$, Navin Rajaratnam ${ }^{2}$, Mallem Pravin Kumar $^{3}$ \\ ${ }^{1}$ (Department of Physiology, Sri Muthukumaran Medical College Hospital and Research Institute, \\ Chennai, Tamil Nadu, India.) \\ ${ }^{2}$ (Department of Physiology, Meenakshi Medical College Hospital and Research Institute, \\ Kanchipuram, Tamil Nadu, India.) \\ ${ }^{3}$ (Department of Physiology, Karpagam Faculty of Medical Sciences and Research, \\ Coimbatore, Tamil Nadu, India.)
}

\begin{abstract}
Semantic verbal fluency tests are used as a measure of cognitive function to assess language and executive function. Secondary to increasing life spans, there are increasing numbers of older individuals at work places. Our study was done to assess the effect of aging on verbal fluency in South Indians. 50 controls aged 20-50 years (Group I), 50 subjects aged 60-75 years (Group II) and 50 subjects aged above 75 years (Group III) of both sexes who were cognitively unimpaired with a minimum $6^{\text {th }}$ standard education took part in the study. The semantic category verbal fluency test and verbal mental tracking test were administered. Comparison of the verbal fluency scores between Group I versus Group II $(p=0.00)$ and Group I versus Group III $(p=0.00)$ was significant. Comparison of the verbal mental tracking scores between Group I versus Group II ( $p=0.002)$ and between Group I versus Group III $(p=0.00)$ was also significant. However there were no significant differences in the number of perseverative errors (repetitions) between controls and subjects. Our study therefore showed that while verbal fluency declined significantly with aging, there was no evidence of cognitive inflexibility and executive dysfunction with aging.
\end{abstract}

Keywords-Aging, Cognition, Cognitive inflexibility, Executive dysfunction, semantic verbal fluency test.

\section{INTRODUCTION}

Cognitive functions include attention, memory, language, constructional ability and other higher cognitive functions like fund of acquired knowledge, abstract thinking, arithmetic computations and judgment. The effect of aging on cognitive function has been found to vary in terms of which function is affected more by aging and also in terms of susceptibility to the effects of aging among different individuals [1]. Some researchers have even found that age related changes in cognitive function were noted before the age of 50 years [2], although generally the cognitive decline is considered to occur later in life.

Many instruments assess the language component of cognitive functions but a simple, short, easy to administer test that is widely used is the semantic verbal fluency test using the category of 'animals' as it is clear across languages and cultures [3]. The semantic verbal fluency test involves the production of semantically related words that belong to different noun or object categories ( $\mathrm{Eg}$; animals, fruits, vegetables) in a given period of time. It has been found that there is a significant negative correlation of the semantic verbal fluency test involving naming animals with age and a significant positive correlation for years of formal education [4]. Females were found to perform better in verbal fluency tests using the category fruits and vegetables [5].

A study done on Brazilian older adults with varied educational backgrounds revealed that education did not have an effect on verbal fluency [6]. Age, education and gender were found to have an effect on neuropsychological measures of fluency in Hong Kong Chinese [7]. A significant age related decrease in executive functioning and verbal fluency was noted in 578 healthy adults aged 64-81 of the Maastricht aging study [8]. A study done using the category (animal) fluency test in Indians, revealed that education directly affected and age inversely affected category fluency [9]. Another study revealed that the semantic verbal fluency of elderly English adults increased by 1.1 extra words a minute between 1991 and 2002 [10]. Although specific norms exist, in general, naming less than 15 animals in the semantic verbal fluency test is considered abnormal in elderly subjects, although for the very old, ten may be acceptable.

Studies have been done to analyze the use of 'clustering' (the ratio of words generated within subcategories) ; and 'switching' (the frequency of shifts between clusters); but no significant benefits of diagnostic value were found to be obtained [11]. The number of perseverative errors (which are repetitions of words already used in that trial by the subject, or use of variations of words used already) are also determined and reflect cognitive inflexibility, which is one aspect of executive dysfunction. In a study done to investigate perseveration in normal aging, no age effects were found for perseveration on the verbal naming tasks [12].

Our interest in studying the effect of aging on cognitive function in general and verbal fluency in particular is because they are competencies that are needed both in young and old age to meet the challenges of education, profession and everyday life. This is even more relevant now with the the increasing lifespan and 
tendency for older individuals to continue working. The semantic category verbal fluency test which is being used in Indian institutions was chosen as it was considered to be simple, easy to understand for subjects and easy to administer.

\section{AIM}

The aim of our study was to determine the effect of aging on the verbal fluency of normal cognitively unimpaired South Indians, using the semantic category verbal fluency test and verbal mental tracking test and to determine the effect of factors like sex and educational status on verbal fluency.

\section{MATERIALS AND METHODS}

This study was done in the Institute of Physiology and Experimental Medicine, Madras Medical College, Chennai and the Department of Geriatric Medicine of Government General Hospital, Chennai in South India. Written informed consent was obtained. 50 controls aged 20-50 years (Group I), 50 subjects aged 60-75 years (Group II) and 50 subjects aged above 75 years (Group III) of both sexes with a minimum $6^{\text {th }}$ standard education took part in the study. The following exclusion criteria were used: Individuals with history or clinical findings of neurological diseases including dementia, stroke, transient ischaemic attacks, depression, Parkinsonism, epilepsy, head injury, brain tumors or brain surgery and individuals with un-corrected visual or auditory defects were excluded.

Screening of the subjects and controls consisting of history and clinical examination was done. The semantic category verbal fluency test was then administered by asking the controls and subjects to generate as many words as possible in a minute, without repetition, under two specific categories - animals (trial1) and first names (trial 2). Verbal mental tracking was also tested by asking them to generate as many pairs as possible in a minute, consisting of one animal with one first name, without repetition. All responses were recorded. The verbal fluency test score was the average of the total number of words generated in the two trials. The verbal mental tracking test score was the number of pairs generated in the test in the one minute period. The number of perseverative errors for both tests was noted as the number of words or variations of words already used that were repeated in that trial. Statistical analysis was done using SPSS. The means and standard deviations of the three groups were calculated and compared. ANOVA and Bonferroni method were used. The effect of sex and educational status on verbal fluency and verbal mental tracking was determined using logistic regression.

\section{RESULTS}

Comparison of the verbal fluency scores between Group I (controls) versus Group II (subjects aged 60-75 years) and Group I (controls) versus Group III (subjects aged above 75 years) was found to be significant. Comparison of the verbal mental tracking scores between Group I versus Group II and between Group I versus Group III was also significant. However there were no significant differences in the number of perseverative errors (repetitions) between controls and subjects (TABLE 1). It was also found that there was a significant relationship between education and the verbal mental tracking test but not the verbal fluency test scores, while there was no relationship between the individual's sex and verbal fluency or verbal mental tracking scores.

TABLE 1 - Comparison of the Semantic Category Verbal Fluency Test scores, Verbal Mental Tracking Test scores and perseverative errors in the three groups.

\begin{tabular}{|c|c|c|c|c|c|}
\hline Test & $\begin{array}{c}\text { Group I } \\
(\text { Mean } \pm \text { SD }) \\
\end{array}$ & $\begin{array}{c}\text { Group II } \\
(\text { Mean } \pm \text { SD })\end{array}$ & $\begin{array}{c}\text { Group III } \\
(\text { Mean } \pm \text { SD) }\end{array}$ & Category & p Value \\
\hline \multirow{3}{*}{ Verbal Fluency } & \multirow{3}{*}{$19.02 \pm 4.10$} & \multirow{3}{*}{$14.82 \pm 3.69$} & \multirow{3}{*}{$12.58 \pm 3.51$} & I vs II & $0.00 *$ \\
\hline & & & & I vs III & $0.00 *$ \\
\hline & & & & II vs III & $0.01 *$ \\
\hline \multirow{3}{*}{$\begin{array}{l}\text { Verbal Fluency } \\
\text {-Errors }\end{array}$} & \multirow{3}{*}{$0.98 \pm 1.29$} & \multirow{3}{*}{$0.72 \pm 0.97$} & \multirow{3}{*}{$0.60 \pm 0.81$} & I vs II & 0.64 \\
\hline & & & & I vs III & 0.21 \\
\hline & & & & II vs III & 1.00 \\
\hline \multirow{3}{*}{$\begin{array}{l}\text { Verbal Mental } \\
\text { Tracking }\end{array}$} & \multirow{3}{*}{$8.38 \pm 1.85$} & \multirow{3}{*}{$7.10 \pm 1.75$} & \multirow{3}{*}{$5.62 \pm 1.90$} & I vs II & $0.00 *$ \\
\hline & & & & I vs III & $0.00 *$ \\
\hline & & & & II vs III & $0.00 *$ \\
\hline \multirow{3}{*}{$\begin{array}{l}\text { Verbal Mental } \\
\text { Tracking-Errors }\end{array}$} & \multirow{3}{*}{$0.38 \pm 0.67$} & \multirow{3}{*}{$0.36 \pm 0.66$} & \multirow{3}{*}{$0.42 \pm 0.70$} & I vs II & 1.00 \\
\hline & & & & I vs III & 1.00 \\
\hline & & & & II vs III & 1.00 \\
\hline
\end{tabular}

Results expressed as mean and standard deviation for each of the three groups, *p value $<0.05$ being considered significant.

\section{DISCUSSION}

This study done to determine the effect of aging on the verbal fluency of normal cognitively unimpaired South Indians, using the semantic category verbal fluency test and verbal mental tracking test, showed that verbal fluency declined significantly with aging. This finding is in agreement with previous studies 
that revealed age related decreases in verbal fluency $[4,7,8,9]$. Comparison of the verbal mental tracking scores between Group I versus Group II and between Group I versus Group III was also significant. This test was comparatively more difficult than the semantic category verbal fluency test involving naming animals in a one minute period and this could explain the findings.

However there were no significant differences in the number of perseverative errors (repetitions) between controls and subjects. As perseverative errors occur due to the individual's tendency to be stuck to a certain response during the test, they reflect cognitive inflexibility, which is one aspect of the broader executive dysfunction. Since no significant differences were noted in the number of perseverative errors made by the controls (Group I), subjects aged 60-75 years (Group II) and subjects aged above 75 years (Group III), our study did not find any evidence of cognitive inflexibility with aging. This finding too is in agreement with that of other researchers who investigated perseveration in normal aging and found no age effects for perseveration on the verbal naming tasks [12].

It was also found that there was a significant relationship between education and the verbal mental tracking test scores only and not the verbal fluency test scores. This finding of our study is in contrast to the findings of other studies [5,7,9], that revealed that there was a positive correlation between education and verbal fluency, but is in agreement with the study on Brazilian older adults where no relationship between education and verbal fluency had been noted [6]. The findings of our study could be explained by the fact that we included only those individuals with a basic minimum education of $6^{\text {th }}$ standard in our study. Still it is to be noted that our study did find however that education did affect the scores of the more difficult verbal mental tracking test. Unlike the study on Hong Kong Chinese [7], in whom there was an effect of gender on verbal fluency scores, no such relationship between the individual's sex and verbal fluency scores was found in our study.

The limitations of our study are the possible inclusion of subjects with occult dementia despite strict inclusion criteria; the fact that this was not a longitudinal study; and less attention being given to qualitative aspects of verbal fluency performance. Further studies can be done to address these issues.

\section{CONCLUSION}

Our study showed that while verbal fluency declined significantly with aging, there was no evidence of cognitive inflexibility and executive dysfunction with aging.

\section{REFERENCES}

[1]. Glisky EL, Changes in Cognitive Function in Human Aging, in Riddle DR (Ed), Brain Aging: Models, Methods, and Mechanisms (Boca Raton, FL: CRC Press, 2007)

[2]. Salthouse TA, What and when of cognitive aging. Curr Dir Psychol Sci 13, 2004,140 - 144,

[3]. Ardila A, Ostrosky-Solís F: Cognitive testing towards the future: The example of Semantic Verbal Fluency (ANIMALS).Int J Psychol 2006, 41(5):324-332

[4]. Benito-Cuadrado MM, Esteba-Castillo S, Bohm P, Cejudo-Bolivar J, Pena-Casanova J. Semantic verbal fluency of animals: a normative and predictive study in a Spanish population. J Clin Exp Neuropsychol. 2002;24:1117-1122.

[5]. Bolla KI, Gray S, Resnick SM, Galante R \& Kawas C (1998). Category and letter fluency in highly educated older adults. Clinical Neuropsychology, 12: 330-338

[6]. Yassuda, M. S., Diniz, B. S., Flaks, M. K., Viola, L. F., Pereira, F. S., Nunes, P. V., \& Forlenza, O. V. (2009). Neuropsychological profile of Brazilian older adults with heterogeneous educational backgrounds. Archives of Clinical Neuropsychology, $24(1), 71-79$.

[7]. Lee, T. M., Yuen, K. S., \& Chan, C. C. (2002). Normative data for neuropsychological measures of fluency, attention, and memory measures for Hong Kong Chinese. Journal of Clinical and Experimental Neuropsychology, 24(5), 615-632.

[8]. van Hooren SAH, Valentijn AM, Bosma H, Ponds RWHM, van Boxtel MPJ, Jolles J: Cognitive functioning in healthy older adults aged 64-81: a cohort study into the effects of age, sex, and education. Neuropsychol Dev Cogn B Aging Neuropsychol Cogn 2007, $14: 40-54$

[9]. Mathuranath, P. S., George, A., Cherian, P. J., Alexander, A., Sarma, S. G., \& Sarma, P. S. (2003). Effects of age, education and gender on verbal fluency. Journal of Clinical and Experimental Neuropsychology, 25(8), 1057-1064.

[10]. Llewellyn, D. J., Matthews, F. E., \& The Medical Research Council Cognitive Function and Ageing Study (MRC CFAS). (2009). Increasing levels of semantic verbal fluency in elderly English adults. Aging, Neuropsychology, and Cognition, 16(4), 433-445.

[11]. Epker, M. O., Lacritz, L. H., \& Munro Cullum, C. (1999). Comparative analysis of qualitative verbal fluency performance in normal elderly and demented populations. Journal of Clinical and Experimental Neuropsychology, 21(4), 425-434.

[12]. Foldi, N. S., Helm-Estabrooks, N., Redfield, J., \& Nickel, D. G. (2003). Perseveration in normal aging: A comparison of perseveration rates on design fluency and verbal generative tasks. Aging, Neuropsychology, and Cognition, 10(4), 268-280. 